\title{
Survey of Sleep Disturbances among Wenzhou-Kean University (WKU) Students
}

\author{
Lingxi Zhang, \\ ${ }^{1}$ Wenzhou-Kean University, Wenzhou China, 325060 \\ *Corresponding author. Email: lingxiz@kean.edu
}

\begin{abstract}
Sleep problems have become one of the most serious health problems facing college students all over the world. This paper is to describe and investigate the phenomenon of sleep disturbances among Chinese college students in Wenzhou Kean University (WKU). This research adopted the descriptive-correlational design, made use of the method of cross-sectional study. Administering the researcher-developed Sleep Disturbances Survey questionnaire to 275 students (131 male and 144 female) in WKU, the sampling technique being used is random sampling method. The data collection will base on the participants' answers to the questionnaire. Their answers will be truthfully recorded and used for further analysis, discussion and research. The study found that WKU students generally have insufficient sleep duration and sleep deprivation, and more than half of them suffer from sleep disturbances, in which long-term or short-term insomnia accounts for a large proportion. The gender difference of sleep disturbances among students is not significant. In addition, the study found that ways to improve sleep quality vary from person to person, but drinking milk, exercising and listening to music are widely used.
\end{abstract}

Keywords: sleep duration, sleep deprivation, sleep disturbances, insomnia, sleep quality

\section{INTRODUCTION}

Sleep disturbances include many different kinds of so-called sleeping problems, which, concretely, encompass poor sleep quality, and sleep difficulties such as difficulty in maintaining sleep and difficulty in initiating sleep [1]. More importantly, sleep disturbances are currently concerned as an important risk factor for the development of depression among the general population [2, 3]. In addition, sleep disturbances are associated with many diseases that threaten people's physical health as well, such as obesity, cardiovascular disease, and some of heart diseases [4].

As college students just transiting from adolescence to adulthood, they usually encounter many challenges. Due to various pressures, such as living independently, adapting to the new social environment, coping with high academic and social pressure and unstable life schedule, many of them are faced with the problems of insufficient sleep and low sleep quality, all of which would increase the risk of sleep disturbance [5].

Irregular sleep habits, delayed sleep time, early rising and insufficient sleep are becoming more and more common among college students all over the world and there is no sign of improvement for this trend $[6,7]$. According to $\mathrm{Li}$ et al.'s research [8], sleep problems have even become one of the most serious health problems faced by Chinese college students as well. Besides, Chinese college students should pay more attention to sleep health. There is not enough special research on Chinese college students' sleep disturbance, which may be one of the reasons why Chinese college students do not pay enough attention to sleep disturbances.

The purpose of this paper is to describe and investigate the phenomenon of sleep disturbances among WKU students. Participants are Chinese college students in WKU.

Specifically, the following sub-objectives are considered:

1. Describing sleep duration of WKU students.

2. Describing and investigating sleep disturbances/ difficulties among WKU students.

3. Describing and investigating phenomenon of insomnia among WKU students.

4. Investigating effective ways to improve sleep problems for WKU students. 


\subsection{Research Questions}

Research Question 1: What is the sleep duration of WKU students?

Research Question 2: How many percentage WKU students are suffering from sleep disturbances/difficulties.

Research Question 3: Is there a significant difference in suffering from sleep disturbances of WKU students by gender?

Research Question 4: What are the effective methods for WKU students to improve sleep problems?

\subsection{Hypothesis}

H0: There is no significant difference in suffering from sleep disturbances of WKU students by gender.

H1: There is a significant difference in suffering from sleep disturbances of WKU students by gender.

\subsection{Conceptual Framework}

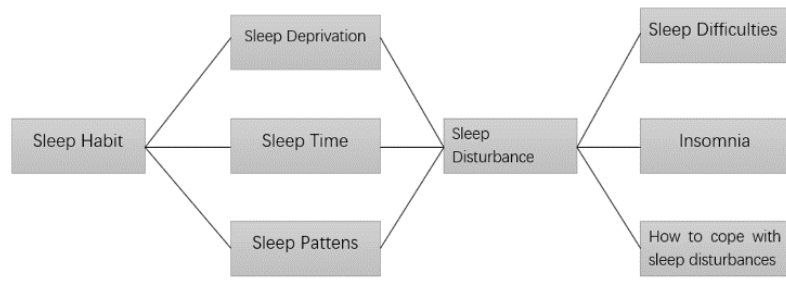

Figure 1 Conceptual Framework

\section{REVIEW OF RELATED LITERATURE AND PAST STUDIES}

\subsection{Sleep Habit}

\subsubsection{Sleep Deprivation}

With the continuous improvement of the quality of human life, scientists and researchers are also deepening the study of sleep duration which is one of the most important factors affecting human health. According to the laboratory studies of experimental sleep deprivation and sleep restriction [9, 10], and the meta-analysis of epidemiological and cohort data [11, 12], the causal relationship between short sleep duration and adverse health outcomes is supported.

There is a significant relationship between sleep deprivation and many diseases that threaten people's health. According to Leproult \& Van Cauter's research [13], insufficient sleep has adverse effects on health through endocrine perturbations and harmful metabolic, affecting various systems of the body, and may lead to serious health problems. Epidemiological studies by many scientists have shown that short sleep duration has a significant relationship with many different types of certain adverse health outcomes, including type 2 diabetes, obesity, hypertension, and metabolic syndrome [11, 14-16].

In addition, a survey of first-year residents found that the reduction of the average night sleep duration will increase the probability of getting mental problems, and sleep problems have a compounding effect, so participant with both sleep disturbances and insufficient/short sleep have the highest risk of disturbance. A study of physicians-in-training found that this group of people is particularly prone to sleep deprivation due to long and prolonged working hours and rotating shift-work schedules, which makes them more prone to emotional instability, irritability and difficulty in concentration [17]. In addition, many studies have found that sleep deprivation is one of the most important factors leading to depression of people $[2,3]$.

Studies on students found that students with sleep deprivation usually performed worse than students with normal sleep pattern, including both academic performance and social performance [18]. In addition, short sleep time is associated with unhealthy risk behaviors, such as drinking alcohol and smoking tobacco, which may increase the risk of hypertension, hypercholesterolemia, diabetes, obesity and even death. Another study of adolescents also found that adolescents' lack of sleep was associated with an increased risk of self-harm, suicidal thoughts and suicide attempts [19].

According to the macro study performed by Matricciani et al., chronic and long-term sleep deprivation is increasingly common in modern society [18]. Sleep deprivation, as well as other sleep problems, is one of the major threats to human health both mentally and physically, which cannot be ignored by the people in the current society, and it must arouse the attention of people in all countries.

\subsubsection{Sleep Time}

Although people's appropriate sleep time varies with age, whether for children or adults, getting enough sleep every day is one of the main principles for their good health. Sleep plays an important role in many physical, cognitive, and psychological processes [20, 21]. Having a suitable sleep time seems to be a necessity for health and vital for survival and development.

Many experts believed that in today's twenty-four-hour working society, the competition between sleep and multitasking is becoming increasingly fierce. It leads to a serious shortening of sleep time all around the world, especially in adolescents [22, 20]. Children aged 6-12 should regularly sleep 9-12 hours every 24 hours, teenagers aged 13-18 should sleep 8-10 hours every 24 hours, and 
people aged 19-24 should sleep 7-8 hours every 24 hours, according to The American Academy of Sleep Medicine's recommendations for optimal health [19]. However, compared with the recommended time, data from the United States show that short sleep time is common among middle school students and high school students.

Compared with adults who have been in society for many years, if children, teenagers and college students do not get the recommended amount of sleep that matches their age, they will not only increase the risk of chronic disease and illness, such as diabetes, obesity and mental health problems, but also cause behavioral problems, that is to say, they are more likely engaging in health- and injury-related risk behaviors with their immature mind [23].

\subsubsection{Sleep Pattens of College Students}

Nowadays, college students are one of the most frequent users of smart phones and electronic devices. According to Exelmans \& Van den Bulck's research, the more and more common use of smart phones and electronic reading devices before going to bed is leading to a gradual change in people's sleep patterns [24]. Data from the United States. showed that in the past 50 years, Americans' sleep time has decreased by 1.5 to 2 hours, which has greatly changed their sleep patterns and affected the next generation of Americans [25]. These information shows that the sleep pattern of college students is becoming unstable, their sleep time is being compressed, and their sleep quality and sleep health are being seriously threatened.

In fact, more and more scholars are realizing that the problem of irregular sleep habits of college students is gradually becoming a global problem. Data from the United States, and Palestine [6, 7]. both show that irregular sleep habits, delayed sleep time, early rising and insufficient sleep are becoming more and more common among college students and there is no sign of improvement for this trend.

There are many reasons for this phenomenon. In addition to the influence of new media and electronic equipment, the external factors also include the lack of parental supervision, the change of campus living environment, the use of caffeine or energy drinks, etc. What's more, college students who just transition from adolescence to adulthood still need to face a lot of psychological pressure. Because of adapting to the new social environment, living independently, confusion about the future, coping with higher learning and social pressure, and unstable life, their hearts will also be tested by strong mental pressure [5]. What is not optimistic is that all of the disadvantages and tests mentioned above that faced by college students will increase their risk of getting sleep disturbances, thereby posing a serious threat to their health.

\subsection{Sleep Disturbances}

\subsubsection{Sleep Difficulties}

The most common sleep difficulty is to start and maintain sleep [26]. These two types of sleep disturbances threaten people's sleep quality and health to a great extent. However, they have not attracted people's due attention in the world. According to Broström et al.'s study, the number of awakenings every night was significantly increased in men, and the ratio of habitual sleep to estimated amount of sleep they need was significantly shortened in women [27]. These two points indicate that the phenomenon of sleep difficulties in both men and women is aggravating. Moreover, their study also showed that compared to patients without sleep difficulties, as well as to the normal people, patients with difficulties in maintaining sleep, starting sleep and waking up in the morning had significantly lower health-related quality of life (HRQOL) in almost all dimensions of SF-36 questionaries. This have proved that sleep difficulty, as a common sleep disturbance, really aggravates people's health risk and greatly threatens people's physical health.

\subsubsection{Insomnia}

According to Stoller's research, insomnia affects $40 \%$ of the population annually, which is an important cause of mortality and morbidity, and conservative estimates of the total economic loss caused by insomnia every year are between 92 billion 500 million and 107 billion 500 million dollars [28].

Insomnia, as a sleep disorder, the main symptom is having serious difficulty in falling asleep. Insomnia is usually accompanied by daytime sleepiness, irritability, low energy and depression mood, according to Roth [29]. Insomnia can occur independently, which can also be caused by other problems. There are many causes of insomnia, including psychological stress, hyperthyroidism, heartburn, endocrine disorders, menopause, usage of some drugs, caffeine, nicotine or alcohol [30].

For people with insomnia, all aspects of their lives will be affected. It can lead to increased risk of vehicle collision, as well as problems with attention and learning. Insomnia can be short-term, lasting for days or weeks, or long-term, lasting more than a month [29]. Long term insomnia can seriously affect people's normal life, even make them lose their social functions or suffer from severe depression. As a common sleep disorder in all ages, insomnia poses a great threat to human health and sleep quality, and is one of the major health risks that cannot be ignored. 


\subsubsection{How to cope with these sleep disturbances}

A very effective way is to try to establish a regular sleep pattern, going to bed and getting up at about the same time every day. This means that your body begins to associate the time of the day with sleep. You may need to do this for a few weeks to build a regular pattern. In addition, it helps to go to bed only when you feel too tired to sleep. If it usually takes a long time for you to fall asleep, put it off until you fall asleep, then get up as usual. This may mean that you spend less time in bed, but more time in bed asleep [31].

Before you try to fall asleep, it is important to relax and get rid of your daily worries. Stop any stimulating activities, such as work or exercise, and do not watch a screen, such as a mobile phone, computer, or tablet, one hour before going to bed [31]. It also helps to do something calming before going to bed, such as listening to relaxing music, doing something creative or taking a bath.

It's also important to make sure before you go to bed that the place you sleep in is comfortable, that is, the temperature, light and noise levels are right for you. People have different opinions about what comfort is, so you may need to try to find the one that suits you best. In general, dark, quiet and cool environments usually make it easier for people to fall asleep [31]. If something special bothers you at night, such as others snoring, or a noisy alarm clock keeps you awake, try to find a solution.

\subsection{Summary}

All in all, it is certain that short sleep duration will increase people's health risk and may lead to a series of physical problems. Besides, sleep deprivation also has a significant relationship with many mental problems as well as lots of kinds of adverse mental states. Social surveys show that chronic and long-term sleep deprivation is increasingly common. In today's competitive society, sleep time is seriously shortened all over the world.

In addition, the sleep habits of young people and young adults should be taken seriously because they are in an important period of physical and psychological development. For college students, more and more studies show that sleep problems have even become one of the most serious health problems faced by college students all over the world. As frequent users of smart phones and electronic devices, college students' sleep pattern and quality are negatively affected. The particularity of College Students makes them have disadvantages that may increase their risk of getting sleep disturbances.

For the general public, more and more people are suffering from sleep difficulties, insomnia and other sleep disturbances. Sleep disturbance aggravates people's health risk and greatly threatens people's physical and mental health. It has already become one of the main threats to modern human's health. But at the same time, through scientific methods, we can use positive actions to prevent and alleviate the problem of sleep disturbances, like establish a sleep routine and relax before we go to bed.

\section{METHODOLOGY}

\subsection{Research Design}

The research will adopt the descriptive-correlational design. The research will focus on investigating the situation of sleep disturbances for contemporary College Students in Wenzhou-Kean University (WKU). At the same time, gender differences will be taken into account in this study, we will study whether there is a significant difference in the percentage of students suffering from sleep disturbances by their gender. This is sample research, and all of the sample being studied will be selected randomly from all student of WKU. In the study, researchers will use cross-sectional study to investigate the situation of sleep disturbances for contemporary WKU students. The study is quantitative. The questionnaire will be randomly distributed on the Internet, and the participants answered the questionnaire voluntarily. This is a retrospective cross-sectional study, through the acquisition of empirical information, to study the basic situation of College Students' sleep health. All the questionnaires that have been answered and successfully submitted will be used as samples for our study. The data collection will base on the participants' answers to the questionnaire. Their answers will be truthfully recorded and used for further analysis, discussion and research. The study population is all undergraduate Chinese college students in WKU. The totally number is about 2770 (exact number of students is showed in Table 1). Researchers will randomly select studies samples and the sample size would be approximately 10 to 15 percent of the whole study population. Therefore, the number of sample size is about 270-410, and the sampling technique being used is random sampling method.

Table 1. Population Composition

\begin{tabular}{|c|c|c|c|c|}
\hline & Freshman & Sophomore & Junior & Senior \\
\hline Female & 906 & 272 & 189 & 267 \\
\hline Male & 622 & 187 & 163 & 166 \\
\hline Total & 1528 & 459 & 352 & 433 \\
\hline
\end{tabular}




\subsection{Research Instrumentation}

In this research, a four-point attitudinal Likert scale will be applied to describe respondents' attitudes. It can specifically separate different levels of respondents' attitudes toward some sub-objectives, and it is very appropriate for the measurement. Like When we need to calculate the student's responses to the scaled questionnaires of the factors affecting sleep. The Likert Scale interpretation is shown in Table 2.

Table 2. Likert Scale Interpretation

\begin{tabular}{|c|c|c|c|}
\hline Response Scale & $\begin{array}{c}\text { Degree of } \\
\text { Intensity }\end{array}$ & Descriptive Interpretation & Mean Interval \\
\hline 4 & Strongly Agree & Very High & $3.51^{\prime}-4.0$ \\
\hline 3 & Agree & High & $2.51-3.5$ \\
\hline 2 & Disagree & Low & $1.51-2.5$ \\
\hline 1 & Strongly Disagree & Very Low & $1.0-1.5$ \\
\hline
\end{tabular}

Note: Legend: Strongly Disagree (1.0-1.5); Disagree (1.51-2.5); Agree (2.51-3.5); Strongly Agree (3.51-4.0)

\subsection{Data Collection Procedures}

For this study, the data collection will base on the participants' answers to the questionnaire, through the acquisition of empirical information, we are able to study the basic situation of College Students' sleep health. The researcher developed an online questionnaire using the website named Wenjuanxing. Then the researcher shares the link through social media like QQ and WeChat for target respondents to access and respond. These platforms are the channel to collect and process the responses of questionnaires, which can provide complete evidence for the data analysis and results interpretation.

\subsection{Data Analysis}

Descriptive and inferential statistics will be used in this study to provide a clear and in- depth data analysis. Data processing will use SPSS to conduct relative charts and graphs. Frequency and percentage will be used to describe the respondents' demographic profile. Mean, standard deviation and ranking will be used to calculate the student's responses to the scaled questionnaires of the factors affecting sleep. T-test will be used to measure the differences of suffering from sleep disturbances of WKU students by gender. The level of significance used for each test is set at 0.05 .

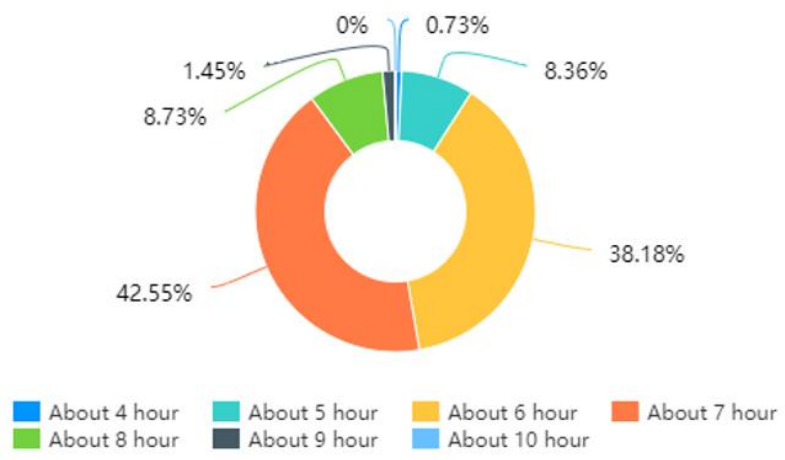

Figure 2 Sleep Duration of WKU students

\section{RESULTS AND DISCUSSION}

As for Research Question 1, Figure 2 below shows the percentage of WKU students based on their sleep duration. Figure 3 below shows the classification of WKU students based on whether they have sleep deprivation or not. According to Figure 2, Most of the participants $(80.73 \%)$ had about 6-7 hours of sleep, of which $42.55 \%$ had about 7 hours of sleep, and $38.18 \%$ had about 6 hours of sleep. It is worth noting that, a total of $47.27 \%$ of the participants had less than 7 hours of sleep. However, people aged 19-24 should sleep 7-8 hours every 24 hours, according to The American Academy of Sleep Medicine's recommendations for optimal health, and the vast majority of WKU students are in this age stage. So, they do not get enough sleep in line with their age [19]. In addition, $73.45 \%$ of the participants reported that they did not think they have enough sleep everyday and had the case of sleep deprivation.

This finding is consistent with previous studies, insufficient sleep duration and the case of sleep deprivation are indeed common among college students, and many young adults in college do not get the sleep time that is consistent with their age.

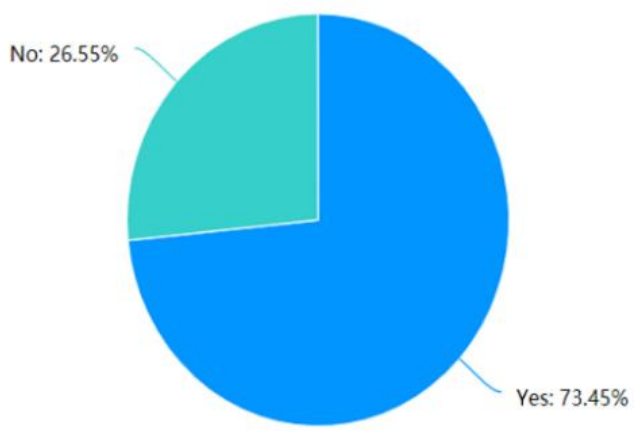

Figure 3 Rates of students on their sleep deprivation or not 
For research question 2, Figure 4 below shows classification of WKU students based on whether they have sleep disturbances or not. $57.45 \%$ of the participants reported they had the case of sleep disturbances. Figure 5 below shows classification of WKU students based on whether they are you troubled by insomnia or not. Among all the participants, $41.09 \%$ of them reported long-term or short-term insomnia.
In this regard, we can draw a conclusion that more than half of WKU students is suffering from sleep disturbances, among them, long-term or short-term insomnia accounts for a large part, and it is a common phenomenon for WKU students.

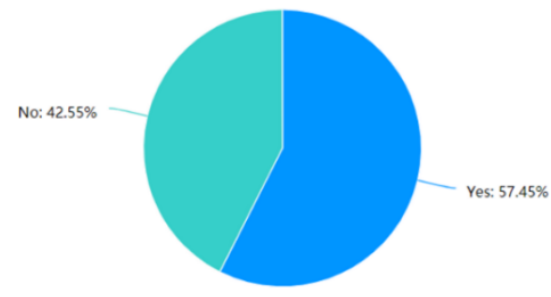

Figure 4 Classification of WKU students based on whether they have sleep disturbances or not.

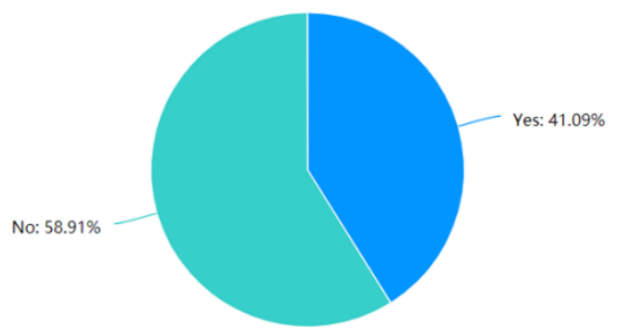

Figure 5 Classification of WKU students based on whether they are troubled by insomnia or not

In terms of research question 3 , the T-test was performed to examine whether there is a significant difference in suffering from sleep disturbances of WKU students by gender. Table 3 and Table 4 presents the mean for male $(\overline{\mathrm{x}}=1.43)$ and female $(\overline{\mathrm{x}}=1.42)$, and the P-value (.897) of the participants' gender in relation to Sleep Disturbances.

The findings reveal there is no significant difference in suffering from sleep disturbances of WKU students by gender. Therefore, the H0: "there is no significant difference in suffering from sleep disturbances of WKU students by gender" is accepted.

This study shows that the situation of suffering from sleep disturbance of male and female students is very similar. The gender difference of sleep disturbance in WKU is not significant.

Table 3. Gender Mean Rank

\begin{tabular}{|c|c|c|c|c|c|}
\hline & Gender & $\mathrm{N}$ & Mean & Std. Deviation & Std. Error Mean \\
\hline \multirow{3}{*}{ Sleep disturbances } & Male & 131 & 1.43 & .497 & .043 \\
\cline { 2 - 6 } & Female & 144 & 1.42 & .496 & .041 \\
\hline
\end{tabular}

Table 4. Significance in Relation for Gender Difference of Suffering from Sleep Disturbance, using T-test

\begin{tabular}{|l|l|l|l|l|l|l|l|}
\hline \multicolumn{2}{|c|}{} & \multicolumn{2}{|c|}{$\begin{array}{l}\text { Levene' s Test for } \\
\text { Equality of Variances }\end{array}$} & \multicolumn{5}{|c|}{ t-test for Equality of Means } \\
\cline { 2 - 8 } & $\mathrm{F}$ & Sig. & $\mathrm{t}$ & $\mathrm{df}$ & $\begin{array}{l}\text { Mean } \\
\text { Difference }\end{array}$ & $\begin{array}{l}\text { Std. Error } \\
\text { Difference }\end{array}$ \\
\hline $\begin{array}{l}\text { sleep } \\
\text { disturbances }\end{array}$ & $\begin{array}{l}\text { Equal variances } \\
\text { assumed }\end{array}$ & .017 & .897 & .065 & 273 & .004 & .060 \\
\hline & $\begin{array}{l}\text { Equal variances } \\
\text { not assumed }\end{array}$ & & & .065 & 270.480 & .004 & .060 \\
\hline
\end{tabular}

For research question 4, Figure 6 below shows classification of WKU students based on which activity could help them sleep. From the results, the number of students in WKU who choose the three main help-sleep 
activities is not much different, and there are great differences in answers to other activities, which shows that there is not an effective sleep aid method that is generally applicable to all people. We should find and choose the most suitable method in practice.
At the same time, on the other hand, all of these three ways, drinking milk, taking exercises, and listening to music, are worth trying methods to improve sleep problems.



Drink milk

Take exercises

Relax by listening to music

Other

Figure 6 Classification of WKU students based on which activity could help them sleep

\section{RECOMMENDATIONS}

\subsection{For School Administrators}

As the manager of the university, School Administrators of WKU and other university should try to arouse students' attention to sleep health of their own through various media, such as the school newspaper, email, or the Internet, and spread more knowledge about sleep health to them, such as the three ways to help sleep and improve sleep quality mentioned in this study.

School administrators at all levels should take action to improve students' sleep health. A large part of the reason why many college students suffer from sleep deprivation is that the school's schoolwork burden is too heavy. Administrators, professors and teachers should communicate more with students and understand the pressure they are facing. Educators should not only pay attention to students' studies and neglect their sleep and mental health.

\subsection{For Further Research}

There is a lot of room for improvement in this study. Due to the limitation of time and region, this study only focuses on one university of WKU, with only 275 samples. Similar studies should be carried out in other regions of China and all around the world. After all, there are great differences in university education among regions, and sleep health is a global problem.

It is highly recommended for researchers all around world to improve or replicated this research. Human sleep health is a huge social issue, and there are many blank areas waiting for researchers to fill in, and there are many problems to be solved. At the same time, here is no doubt that more research in this field is helpful to arouse people's attention to sleep health.

\section{CONCLUSION}

This study investigated the phenomenon of sleep disturbances among college students in Wenzhou Kean University. The survey of sleep duration shows that insufficient sleep duration and the case of sleep deprivation are common among WKU students. As young adults, many of them do not get enough sleep for their age, which is generally consistent with the results of many sleep studies conducted at universities all around the world.

In the survey of sleep disorders, it is found that more than half of WKU students suffer from sleep disturbances, in which long-term or short-term insomnia accounts for a large proportion, which is a common phenomenon of students, and needs to arouse the attention and vigilance of all college students in WKU. In the study of gender differences in sleep disturbance, we found there is no significant difference in suffering from sleep disturbances of WKU students by gender. The gender difference of sleep disturbance in WKU is not obvious.

Finally, in the study of effective ways to help sleep and improve sleep problems, it is found that the ways to improve sleep quality vary greatly from person to person, but at the same time, it is also found that the three main ways to help sleep-drinking milk, taking exercises, and listening to music, have a wide application and are worthy of promotion.

Most of the conclusions about WKU students' sleep health obtained in this study are not optimistic, which should arouse the attention and vigilance of students, 
schools and all aspects of society. Besides, more large-scale research should also be carried out.

There are also limitations within this study. Some of questions about sleep are a little bit private and personal, and it is not easy to get objective answers from the participants for those questions. Although the vast majority of the questionnaire questions do not involve any personal privacy, it can be expected that there will still be situations where participants are unwilling to answer individual questions or answer truthfully. This may also cause us to face the problem that the sample size of the study is insufficient, which cannot accurately reflect the overall situation. In addition, since going to bed early is more in line with social expectations, the average sleep time of WKU college students obtained by the questionnaire survey may be longer.

In this study, we use random sampling method. The questionnaire was randomly distributed on the Internet, and the participants answered the questionnaire anonymously. However, this may prevent our research sample from reflecting the general population, that is, the overall situation of all college students in WKU, thus causing "sample bias" or "selection bias". Besides, in this case, the people who answered our survey questions may not be a truly random sample, because we may post the questionnaire survey in some specific online student groups, which may also lead to errors.

\section{AUTHORS' CONTRIBUTIONS}

This paper is independently completed by Lingxi Zhang.

\section{ACKNOWLEDGEMENTS}

My sincere gratitude goes first and foremost to students of Wenzhou Ken University for their cooperation and support for this study. Second, I would like to express my heartfelt gratitude to Professor Leah Li V. Echiverri for her guidance and my parents for their supports.

\section{REFERENCES}

[1] Kalmbach, D. A., Arnedt, J. T., Song, P. X., Guille, C., \& Sen, S. Sleep Disturbance and Short Sleep as Risk Factors for Depression and Perceived Medical Errors in First-Year Residents. Sleep, 40(zsw073), 2017. https://doi.org/10.1093/sleep/zsw073.

[2] Drake, C. L., Pillai, V., \& Roth, T. Stress and Sleep Reactivity: A Prospective Investigation of the Stress-Diathesis Model of Insomnia. Sleep, 2014, 37(8), 1295-1304.

[3] Lee, E., Cho, H. J., Olmstead, R., Levin, M. J., Oxman, M. N., \& Irwin, M. R. Persistent Sleep Disturbance: A Risk Factor for Recurrent
Depression in Community-Dwelling Older Adults Sleep, 2013, 36(11), 1685-1691.

[4] Hale, L., Troxel, W., \& Buysse, D. J. Sleep Health: An Opportunity for Public Health to Address Health Equity. Annual Review of Public Health, 2020, 41(1), 81-99.

[5] Peltzer, K., \& Pengpid, S. Nocturnal sleep problems among university students from 26 countries. Sleep and Breathing, 2015, 19(2), 499-508.

[6] Lund, H. G., Reider, B. D., Whiting, A. B., \& Prichard, J. R. Sleep Patterns and Predictors of Disturbed Sleep in a Large Population of College Students. Journal of Adolescent Health, 2010, 46(2), 124-132.

[7] Sweileh, W. M., Ali, I. A., Sawalha, A. F., Abu-Taha, A. S., Zyoud, S. H., \& Al-Jabi, S. W. Sleep habits and sleep problems among Palestinian students. Child and Adolescent Psychiatry and Mental Health, 2011, 5(1), 25.

[8] Li, L., Wang, Y.-Y., Wang, S.-B., Li, L., Lu, L., Ng, C. H., Ungvari, G. S., Chiu, H. F. K., Hou, C.-L., Jia, F.-J., \& Xiang, Y.-T. Sleep Duration and Sleep Patterns in Chinese University Students: A Comprehensive Meta-Analysis. Journal of Clinical Sleep Medicine: JCSM: Official Publication of the American Academy of Sleep Medicine, 2017, 13(10), 1153-1162.

[9] Calvin, A. D., Carter, R. E., Adachi, T., Macedo, P. G., Albuquerque, F. N., van der Walt, C., Bukartyk, J., Davison, D. E., Levine, J. A., \& Somers, V. K. Effects of Experimental Sleep Restriction on Caloric Intake and Activity Energy Expenditure. Chest, 2013, 144(1), 79-86.

[10] King, C. R., Knutson, K. L., Rathouz, P. J., Sidney, S., Liu, K., \& Lauderdale, D. S. Short Sleep Duration and Incident Coronary Artery Calcification. JAMA, 2008, 300(24), 2859-2866.

[11] Chaput, J.-P., McNeil, J., Després, J.-P., Bouchard, C., \& Tremblay, A. Short sleep duration as a risk factor for the development of the metabolic syndrome in adults. Preventive Medicine, 2013, 57(6), 872-877.

[12] Spiegel, K., Leproult, R., \& Van Cauter, E. Impact of sleep debt on metabolic and endocrine function. The Lancet, 1999, 354(9188), 1435-1439.

[13] Leproult, R., \& Van Cauter, E. Role of Sleep and Sleep Loss in Hormonal Release and Metabolism. In Endocrine Development, 2010, Vol. 17, pp. 1121. 
[14] Cappuccio, F. P., D'Elia, L., Strazzullo, P., \& Miller, M. A. Quantity and Quality of Sleep and Incidence of Type 2 Diabetes: A systematic review and meta-analysis. Diabetes Care, 2010, 33(2), $414-420$.

[15] Chaput, J.-P., Després, J.-P., Bouchard, C., \& Tremblay, A. The Association Between Sleep Duration and Weight Gain in Adults: A 6-Year Prospective Study from the Quebec Family Study. Sleep, 2008, 31(4), 517-523.

[16] Knutson, K. L., Van Cauter, E., Rathouz, P. J., Yan, L. L., Hulley, S. B., Liu, K., \& Lauderdale, D. S. Association Between Sleep and Blood Pressure in Midlife: The CARDIA Sleep Study. Archives of Internal Medicine, 2009, 169(11), 1055-1061.

[17] Rosen, I. M., Gimotty, P. A., Shea, J. A., \& Bellini, L. M. Evolution of Sleep Quantity, Sleep Deprivation, Mood Disturbances, Empathy, and Burnout among Interns. Academic Medicine, 2006, 81(1).

[18] Matricciani, L., Olds, T., \& Petkov, J. In search of lost sleep: Secular trends in the sleep time of school-aged children and adolescents. Sleep Medicine Reviews, 2012, 16(3), 203-211.

[19] Paruthi, S., Brooks, L. J., D'Ambrosio, C., Hall, W. A., Kotagal, S., Lloyd, R. M., Malow, B. A., Maski, K., Nichols, C., Quan, S. F., Rosen, C. L., Troester, M. M., \& Wise, M. S. Consensus Statement of the American Academy of Sleep Medicine on the Recommended Amount of Sleep for Healthy Children: Methodology and Discussion. Journal of Clinical Sleep Medicine: JCSM: Official Publication of the American Academy of Sleep Medicine, 2016, 12(11), 1549-1561.

[20] Diekelmann, S., \& Born, J. The memory function of sleep. Nature Reviews Neuroscience, 2010, 11(2), 114-126.

[21] Dolgin, E. Deprivation: A wake-up call. Nature, 2013, 497(7450), S6-S7.

[22] Bin, Y. S., Marshall, N. S., \& Glozier, N. Secular trends in adult sleep duration: A systematic review. Sleep Medicine Reviews, 2012, 16(3), 223-230.

[23] Wheaton, A. G., Jones, S. E., Cooper, A. C., \& Croft, J. B. Short Sleep Duration Among Middle School and High School Students-United States, 2015. Morbidity and Mortality Weekly Report, 2018, 67(3), 85-90.
[24] Exelmans, L., \& Van den Bulck, J. Bedtime mobile phone use and sleep in adults. Social Science \& Medicine, 2016, 148, 93-101.

[25] Fukuda, K., \& Ishihara, K. Age-related changes of sleeping pattern during adolescence. Psychiatry and clinical neurosciences. 2001, 55. 231-2. 10.1046/j.1440-1819.2001.00837.x.

[26] Barnes, C. M., Lucianetti, L., Bhave, D. P., \& Christian, M. S. "You Wouldn't Like Me When I' m Sleepy: Leaders' Sleep, Daily Abusive Supervision, and Work Unit Engagement Academy of Management Journal, 2014, 58(5), 1419-1437.

[27] Broström, A., Strömberg, A., Dahlström, U., \& Fridlund, B. Sleep Difficulties, Daytime Sleepiness, and Health-related Quality of Life in Patients With Chronic Heart Failure. Journal of Cardiovascular Nursing, 2004, 19 (4).

[28] Stoller M. K. Economic effects of insomnia. Clinical therapeutics, 1994, 16 (5), 873854.

[29] Roth Thomas. Insomnia: Definition, Prevalence, Etiology, and Consequences. Journal of Clinical Sleep Medicine, 2007, 3(5 suppl), S7-S10.

[30] Harvey, A. G., \& Tang, N. K. Y. (Mis)perception of sleep in insomnia: A puzzle and a resolution. Psychological Bulletin, 2012, 138(1), 77-101.

[31] Mind (National Association for Mental Health). How to cope with sleep problems. 2017, pp. 9-16. ISBN 978-1-906759. 